\title{
Changes in the biochemical constituents and morphologic appearance of the human cervical stroma during pregnancy
}

\author{
Kristin Myers ${ }^{a}$, Simona Socrate ${ }^{a, *}$, Dimitrios Tzeranis ${ }^{a}$, Michael House ${ }^{b}$ \\ a Department of Mechanical Engineering, Massachusetts Institute of Technology, Cambridge, MA, USA \\ ${ }^{\mathrm{b}}$ Division of Maternal-Fetal Medicine, Tufts Medical Center, Boston, MA, USA
}

A R T I C L E I N F O

\section{Keywords:}

Uterine cervix

Remodeling

Tissue composition

Collagen morphology

FACE assay

Second harmonic generation

\begin{abstract}
A B S T R A C T
Objective: The cervix is the lower portion of the uterus. It is composed of fibrous tissue and its mechanical integrity is crucial for maintaining a healthy gestation. During normal pregnancy, the cervical extracellular matrix (ECM) remodels in preparation for labor. The objective of this study was to investigate the biochemical and morphological changes in cervical stroma associated with physiological remodeling during normal pregnancy.

Study design: Using human cervical tissue obtained from pregnant and non-pregnant patients, the ECM was analyzed for its biochemical constituents and histologic morphology. The ECM was assayed for hydration, collagen concentration, collagen solubility, total sulfated glycosaminoglycan concentration, and individual disaccharide concentration. The ECM morphology was visualized using conventional histological techniques (Masson's trichrome stain, polarized light microscopy) as well as second harmonic generation (SHG) imaging.

Results: When comparing pregnant to non-pregnant tissue, significant increases were measured for total sulfated glycosaminoglycans, hyaluronic acid, and collagen solubility. The microscopy studies confirmed that the collagenous network of the cervical stroma was anisotropic and pregnancy was associated with a discernable decrease in collagen organization.

Conclusion: Significant changes were seen in the concentration and organization of cervical ECM constituents during normal pregnancy.
\end{abstract}

() 2009 Elsevier Ireland Ltd. All rights reserved.

\section{Introduction}

This study investigates the biochemical constituents and morphology of non-pregnant and pregnant human cervical specimens. The cervix is the lower portion of the uterus, with a central canal connecting the uterine cavity to the vaginal birth canal. During normal pregnancy, the cervix remains closed while the uterus expands to allow fetal growth. Hence, the cervix is thought to have important load bearing functions: to withstand the weight of the uterine contents and to resist the tensile forces in the uterine walls. Failure to resist the deformation induced by these loads would result in premature cervical dilation.

The load bearing function of the cervix is reflected in the content of its stroma. In contrast to the uterus, which mainly consists of smooth muscle, the cervix is composed of collagenous ECM with a low degree (5-10\%) of cellularity [1]. The two primary cell types of the stroma are fibroblasts (approximately 85\%) and

\footnotetext{
* Corresponding author at: MIT E25-406, 77 Massachusetts Ave, Cambridge, MA 02139, USA. Tel.: +1 6174522689.

E-mail address: ssocrate@mit.edu (S. Socrate).
}

smooth muscle cells (15\%) [2]. The ECM of cervical stroma is mainly composed of a collagen network embedded in a viscous "ground substance" containing highly hydrated glycosaminoglycans. The presence of elastin has also been documented [2]. Average levels of hydration between $74.4 \%$ and $81.1 \%$ have been measured for non-pregnant cervical stroma, and pregnancy has been found to be associated with an approximate $5 \%$ increase in tissue hydration [3-6].

Studies of cervical collagen focused on three areas: (1) total collagen concentration, (2) collagen solubility, and (3) collagen architecture. The collagen network contains collagen types I and III and accounts for, approximately, 70\% of the tissue dry weight [7]. Regarding total collagen concentration, apparent disagreements between studies are likely a consequence of differences in the conventions used [2]. While collagen concentration normalized per tissue dry weight does not appear to change significantly between the pregnant and non-pregnant tissue $[2,8,9]$, collagen concentration normalized per tissue wet weight appears to decrease due to the increased hydration levels $[4,3,10]$. The most consistent change observed in association with collagen remodeling during pregnancy is an increase in collagen solubility $[4,6,8,9,11,12]$. The largest increase in collagen solubility was 
measured in postpartum specimens [8]. Collagen architecture has been investigated with both X-ray diffraction [13] and magnetic resonance diffusion tensor imaging [14] using non-pregnant cervical specimens. These studies indicate that the cervical collagen network displays some degree of preferential alignment (anisotropy). In both studies, researchers identified three seamless zones of structured collagen in the stroma surrounding the cervical canal: the innermost and outermost rings of stroma contain collagen fibers preferentially aligned in the longitudinal direction, and the middle layer contains collagen fibers preferentially aligned in the circumferential direction.

Glycosaminoglycans (GAGs) in cervical tissue consist of sulfated GAGs and hyaluronic acid (HA). The sulfated GAGs are primarily present in the form of small leucine-rich proteoglycans (SLRPs), such as decorin and biglycan. The SLRPs contain specific collagen binding sites and contribute to the organization of the collagen network. Multiple studies have noted a change in glycosaminoglycan concentrations during pregnancy $[3,9,15,16]$. Shimizu et al. [5] found that the hyaluronic acid, chondroitin sulfate, heparan sulfate and acidic glycosaminoglycan content increased in the postpartum cervix compared to the non-pregnant cervix. Dermatan sulfate (primarily associated with decorin) was the only GAG that was found to decrease with cervical remodeling. A study conducted by Rath et al. [15] reported an increase in total glycosaminoglycans during pregnancy, but a large decrease in dermatan sulfate at time of parturition. The changes in proteoglycan content were found to occur primarily with the onset of labor. In particular, the decrease in dermatan sulfate and increase in HA are believed to play a fundamental role in the disruption of the collagen network $[15,16]$.

The investigation of structure-function relationships for human cervical tissue has been hampered by the general scarcity of mechanical data in the literature, and the limited number of studies in which biochemical and mechanical analyses were conducted on the same specimens. In prior work [7,17] we introduced a stringent protocol for measurement of the mechanical properties of cervical tissue and reported preliminary findings on the tissue response in uniaxial loading. The objective of the current work was (1) to identify appropriate protocols to determine biochemical and morphological characteristics that relate to the mechanical response of the tissue and (2) to investigate these characteristics in the same cervical specimens for which mechanical properties were measured $[7,17]$. The data are grouped according to the patient's obstetric history following the same classification used in prior work [7,17], allowing potential correlation of these results with the mechanical findings. An improved understanding of the structure-function relationships for cervical tissue might be especially valuable in elucidating the etiology of pathological conditions associated with abnormalities of the cervical ECM, such as cervical insufficiency $[6,18]$.

\section{Methods}

\subsection{Tissue harvest}

Hysterectomy specimens were obtained from (1) pre-menopausal women with benign gynecological conditions and (2) pregnant women undergoing cesarean hysterectomy. The pregnant patients underwent cesarean hysterectomy because of suspected placenta accreta or percreta and did not labor. Approval from the Institutional Review Board was obtained from both Tufts Medical Center and MIT. The uterus and cervix were excised from the patients and placed on ice. After visual inspection, each cervix was cut into four $4 \mathrm{~mm}$ parallel disks, perpendicular to the inner canal, using a custom designed stainless steel sectioning tool [7]. Each cervical slice was labeled to distinguish its position relative to the internal and external os. For biochemical assays, stroma specimens ( $\sim 20 \mathrm{mg}$ wet weight) were excised adjacent to the location of the mechanical testing specimens [7,17] and stored at $-80^{\circ} \mathrm{C}$. For morphology studies, cuboidal samples ( $\sim 25 \mathrm{mg}$ wet weight) were excised from the stroma region, placed in Optimum Cutting Temperature (OCT) embedding medium and stored at $-80^{\circ} \mathrm{C}$. Following $[7,17]$ all samples were labeled and classified in three groups according to the patient's obstetric history:

(NPND) samples from non-pregnant patients with no previous vaginal deliveries;

(NPPD) samples from non-pregnant patients with previous vaginal deliveries;

(PCS) samples from pregnant patients collected at the time of cesarean section.

\subsection{Homogenization}

The cervical tissue was homogenized and pulverized before all biochemical assays. To pulverize the tissue, approximately $20 \mathrm{mg}$ of wet tissue was enclosed in aluminum foil and flash frozen in liquid nitrogen. The frozen tissue was then crushed within a precooled stainless steel chamber. The crushed tissue was placed into pre-weighed $1.5 \mathrm{ml}$ eppendorf centrifuge tubes, and the tubes were re-weighed to calculate the tissue wet tissue weight. The samples were stored at $-80^{\circ} \mathrm{C}$ until time of biochemical assay. Care was taken not to let the tissue thaw before testing.

\subsection{Hydration assay}

The tissue hydration was calculated by subtracting the dry weight from the wet weight and normalizing by the wet weight. Sample weights were taken in pre-weighed $1.5 \mathrm{ml}$ eppendorf tubes on a microbalance. Wet weight was measured after pulverization, and dry weight was measured after $24 \mathrm{~h}$ of freeze drying under vacuum at $-20^{\circ} \mathrm{C}$.

\subsection{Sulfated glycosaminoglycan-dimethylmethylene blue (DMB) assay}

Sulfated glycosaminoglycans (GAGs) content was measured using a standard DMB (dimethylmethylene Blue) assay [19] with chondroitin-6-sulfate (Sigma-Aldrich) as the standard. Approximately $20 \mathrm{mg}$ of wet cervical tissue was pulverized and then freeze-dried overnight. The dry tissue was then incubated overnight in $1 \mathrm{ml}$ of $0.1 \mathrm{mg} / \mathrm{ml}$ solution of proteinase $\mathrm{K}$ (Roche Applied Science) at $60^{\circ} \mathrm{C}$. After incubation, the tissue was assayed for sulfated GAGs using a 1,9-dimethylmethylene blue dye (Polyscience Inc.). A spectrophotometer measured the absorbency of the samples at a wavelength of $520 \mathrm{~nm}$. A calibration curve was derived from the chondroitin- 6 sulfate standards. All calibration curves were a second order polynomial fit to the standard data points. The sulfated GAG weight was normalized by tissue dry weight to calculate sulfated GAG concentration.

\subsection{Fluorophore-assisted carbohydrate electrophoresis (FACE) GAG assay}

The individual disaccharides of the glycosaminoglycan chains of the cervical tissue were measured using the (FACE) protocol developed by Calabro et al. [20,21]. The protocol was specialized for cervical tissue by including a serial enzymatic digestion of the tissue with Chondroitinase ABC and Hyaluronidase (Seikagaku Co.). Tubes of disaccharide standards (Sigma-Aldrich) were prepared with $5 \mu \mathrm{g}$ of: chondroitin disaccharide $\Delta$ di-0S, chondroitin disaccharide $\Delta$ di-2S, chondroitin disaccharide $\Delta$ di-4S, 
chondroitin disaccharide $\Delta$ di-6S, and hyaluronic acid disaccharide $\Delta$ di-HA. All standards were prepared by reconstituting each salt in double distilled water at a concentration of $1 \mathrm{mg} / \mathrm{ml}$, and then $5 \mu \mathrm{l}$ of each standard was aliquoted into a single tube and stored at $-80^{\circ} \mathrm{C}$. Cervical tissue samples were pulverized and freeze dried overnight. The dry tissue was then incubated overnight at $60{ }^{\circ} \mathrm{C}$ in $1 \mathrm{ml}$ of $0.1 \mathrm{mg} / \mathrm{ml}$ solution of proteinase $\mathrm{K}$ (Roche Applied Science). The digests were boiled for $5 \mathrm{~min}$ to inactivate the proteinase $\mathrm{K}$, and then cooled to room temperature. Then the samples were centrifuged to recover the supernatants while the undigested tissue was discarded. The supernatants were then run through a Microcon 3 filter (Millipore) in a centrifuge ( $45 \mathrm{~min}, 9500 \times \mathrm{g}$ at room temperature). The GAGs were collected by turning the filters over and spinning them down in a centrifuge ( $3 \mathrm{~min}, 1000 \times g)$. $5 \mu \mathrm{g}$ of GAG from each sample was placed in a separate tube and freeze dried overnight. The dried GAGs were then digested overnight at $37^{\circ} \mathrm{C}$ with Chondroitinase $\mathrm{ABC}$ (Seikagaku Co.) in an ammonium acetate buffer at pH 7 (making sure all solids were dissolved in the enzyme solution). After incubation, the samples were cooled and then recovered in ice-cold ethanol for $2 \mathrm{~h}$ and freeze dried. The dried contents were then digested overnight at $37{ }^{\circ} \mathrm{C}$ with Hyaluronidase (Seikagaku Co.) in an ammonium acetate buffer at pH 7 (making sure all solids were dissolved in the enzyme solution). After incubation, the samples were cooled and then recovered in ice-cold ethanol for $2 \mathrm{~h}$ and freeze dried. The freeze dried digests and disaccharide standards were fluorotagged overnight at $37{ }^{\circ} \mathrm{C}$ by reductive amination with 2 -aminoacridone (Sigma-Aldrich). The tagged specimens were stored at $-80^{\circ} \mathrm{C}$ for up to 3 months until the day of gel assay. Once the specimens were ready to assay, $30 \mu \mathrm{l}$ of $25 \%$ glycerol was added to each specimen and standards tube. $10 \mu \mathrm{l}$ of each sample was loaded into separate lanes of a pre-made Glyco MONO Face gel (Glyco Inc.), with the standards loaded into the first and last lane. The samples were run at a constant voltage of $400 \mathrm{~V}$ for $1 \mathrm{~h}$ and $20 \mathrm{~min}$. After electrophoresis, the gel was imaged using an ultraviolet light in a BioRad imaging station (Molecular Imager ChemiDoc XRS). The gel image was saved and analyzed using the BioRad Quantity 1 Software. The intensity of the sample bands were measured and compared to the standard lanes using the volume tool.

\subsection{Collagen concentration-hydroxyproline assay}

Collagen concentration was measured following a standard hydroxyproline assay referenced in Woessner [22] and Stegemann and Stalder [23]. Hydroxyproline in dried tissue samples was measured using a colorimetric procedure, and was converted into a collagen weight using a mass ratio of collagen to hydroxyproline of $7.46: 1$. The collagen weight was normalized by tissue dry weight to calculate collagen concentration.

\subsection{Collagen extractability (solubility)}

Collagen solubility was measured by extracting approximately $20 \mathrm{mg}$ of wet pulverized tissue in $0.5 \mathrm{M}$ acetic acid containing $1 \mathrm{mg} / \mathrm{ml}$ of pepsin $\left(150 \mu \mathrm{l} / \mathrm{mg}\right.$ wet tissue) for 3 days at $4{ }^{\circ} \mathrm{C}$. The sample was centrifuged at $15,000 \times g$ for $1 \mathrm{~h}$ and the supernatant and tissue pellet were stored at $-80^{\circ} \mathrm{C}$. The hydroxyproline content was measured in the tissue pellet and the supernatant. The extractability is defined as the ratio between the hydroxyproline in the supernatant and the total amount of hydroxyproline.

\subsection{Masson's trichrome stain and light microscopy}

OCT embedded tissue blocks were stored at $-80{ }^{\circ} \mathrm{C}$ until time of cryosectioning. Tissue blocks were sectioned into $8 \mu \mathrm{m}$ thick slices using a freezing microtome, and then stored at $-80^{\circ} \mathrm{C}$ until time of fixation. Tissue slides were fixed, stained and imaged at the Tufts Medical Center pathology lab, following standard protocols [24].

\subsection{Sirius Red stain and polarized light microscopy}

Tissue slides, with $8 \mu \mathrm{m}$ thick tissue slices, were prepared as described above, and stained with $0.1 \%$ Sirius Red F3BA in saturated picric acid, as described in Clark et al. [25]. Digital images were captured with a camera connected to a microscope at $200 \times$ magnification (Olympus MagnaFirge: Optronics Goleta, CA) at the Women and Infants Hospital of Rhode Island. Multiple images were taken of each specimen at the same camera settings. The area of the field above a fixed, common background grey threshold value was calculated for each image and then divided by the total imaged area. Each tissue sample was imaged at 8 random locations, and for each location the percentage of the area occupied by organized collagen (as measured by enhanced birefringence) was recorded. The percentage of the field above the background threshold is a quantitative measure of the tissue birefringence, which correlates with the degree of collagen organization.

\subsection{Second harmonic generation}

Second harmonic imaging is a novel imaging method based on the non-linear scattering of light by arrays of proteins, including collagen, that possess particular optical properties [26]. The OCT embedded tissue blocks were cryosectioned into $50 \mu \mathrm{m}$ thick slices onto microscope slides. The tissue slides were then stored at $-80{ }^{\circ} \mathrm{C}$ until time of imaging. Care was taken to mark the anatomical direction and location of each specimen. No staining or fixation was used before imaging the specimens. Second harmonic generation (SHG) imaging was performed in the So Lab at MIT, with a custom multicolor multiphoton fluorescence microscope with single-photon counting sensitivity [27]. Excitation was at $890 \mathrm{~nm}$ using a mode-locked titanium-sapphire pulsed laser with about 100 femtosecond pulse width (Mira 900, Coherent Inc., Palo Alto, CA). At this excitation wavelength, collagen fibers are easily visualized via the emission of light at exactly half the laser wavelength (second harmonic). The excitation light power at the specimen was $5 \mathrm{~mW}$. For each specimen, the acquired image covers a $2 \mathrm{~mm} \times 2 \mathrm{~mm}$ area. The pixel residence time and the frame acquisition time were $100 \mu \mathrm{s}$ and $7 \mathrm{~s}$, respectively. The depth of the imaging plane was approximately $30 \mu \mathrm{m}$.

\subsection{Statistical analysis}

Human cervical hysterectomy specimens, especially specimens from pregnant patients, are difficult to obtain. In order to improve the statistical power of this study, we have pooled all preliminary data from a previous study [7] with the new data collected for this study. The total (pooled) numbers of cervices obtained for each of the three obstetric history groups, NPND, NPPD, and PCS, were, respectively, 6,11 , and 4 . Multiple specimens at different anatomical locations were obtained from each cervix. The assays conducted in the preliminary study [7], comprising tissue hydration, collagen concentration, collagen extractability, and total sulfated GAGs, followed protocols identical to those used in the current study. Not all specimens were subjected to the complete spectrum of assays described above, as some of the assays were developed at a later stage of this study. The exact number of cervices/specimens corresponding to each assay is provided in Table 1. Two separate comparisons were performed when analyzing the data. First, all non-pregnant specimens were pooled and compared to the pregnant specimens. Second, the two non-pregnant cases were compared to each other. For each 
Table 1

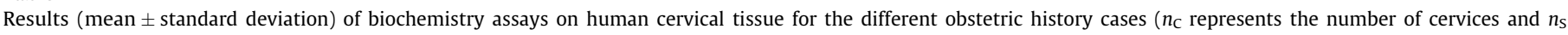
represents the total number of specimens tested for each case).

\begin{tabular}{|c|c|c|c|c|c|c|c|c|c|}
\hline & \multicolumn{9}{|c|}{ Obstetric history } \\
\hline & \multicolumn{3}{|l|}{ NPND } & \multicolumn{3}{|l|}{ NPPD } & \multicolumn{3}{|l|}{ PCS } \\
\hline & & $n_{\mathrm{C}}$ & $n_{\mathrm{S}}$ & & $n_{\mathrm{C}}$ & $n_{\mathrm{S}}$ & & $n_{\mathrm{C}}$ & $n_{\mathrm{S}}$ \\
\hline Hydration [(wet wt. - dry wt.)/wt.] & $74.9 \pm 7 \%$ & 6 & 46 & $75.9 \pm 8 \%$ & 11 & 106 & $81.0 \pm 5 \%$ & 4 & 18 \\
\hline Sulfated GAG concentration [mg/mg dry wt.] & $1.62 \pm 0.56 \%$ & 5 & 23 & $1.52 \pm 0.98 \%$ & 9 & 29 & $2.55 \pm 0.85 \%$ & 3 & 6 \\
\hline \multicolumn{10}{|l|}{ Disaccaride content [mg/mg GAG] } \\
\hline$\Delta$ di-OS & $0.033 \pm 0.006$ & 2 & 4 & $0.039 \pm 0.005$ & 3 & 9 & $0.037 \pm 0.004$ & 3 & 11 \\
\hline$\Delta$ di-4S & $0.187 \pm 0.039$ & 2 & 4 & $0.216 \pm 0.021$ & 3 & 9 & $0.168 \pm 0.044$ & 3 & 11 \\
\hline$\Delta$ di-6S & $0.042 \pm 0.009$ & 2 & 4 & $0.056 \pm 0.008$ & 3 & 9 & $0.065 \pm 0.009$ & 3 & 11 \\
\hline$\Delta$ di-HA & $0.032 \pm 0.006$ & 2 & 4 & $0.050 \pm 0.019$ & 3 & 9 & $0.096 \pm 0.020$ & 3 & 11 \\
\hline Collagen concentration [mg/mg dry wt.] & $70.8 \pm 8.5 \%$ & 4 & 28 & $77.3 \pm 9.1 \%$ & 8 & 22 & $77.6 \pm 9.8 \%$ & 2 & 8 \\
\hline Soluble collagen [mg soluble $\mathrm{OH} / \mathrm{mg}$ total $\mathrm{OH}$ ] & $31.8 \pm 7.0 \%$ & 3 & 9 & $40.5 \pm 11.1 \%$ & 7 & 18 & $80.7 \pm 10.5 \%$ & 3 & 8 \\
\hline
\end{tabular}

comparison, the mean, standard deviation, and the number of cervices tested were used to compare the biochemical findings between the two groups with a standard Student's $t$-test. Differences between the two groups were considered significant if the $p$-value was less than 0.05 .

\section{Results}

Table 1 reports the means and standard deviations of the measured biochemical content for the different obstetric history cases $\left(n_{\mathrm{C}}\right.$ represents the number of cervices and $n_{\mathrm{S}}$ represents the total number of specimens tested for each obstetric history case).

\subsection{Hydration}

The mean hydration level of pregnant tissue (81\%) was found to be higher than the mean level (75.5\%) for non-pregnant tissue. Due to the large observed biological variability between tissue samples, this difference was not found to be statistically significant (Student's $t$-test, $p=0.09$ ), though statistical significance could be probably attained with an increased number of samples. No significant difference in hydration level was found when comparing the two non-pregnant cases. These results are in good agreement with previously reported levels of tissue hydration [4-6] with a $\sim 5 \%$ increase for pregnant tissue.

\subsection{Total sulfated glycosaminoglycan-dimethylmethylene blue (DMB) assay}

A nearly two-fold increase was measured for the concentration of sulfated glycosaminoglycans in the pregnant tissue when compared to the non-pregnant tissue (Student's $t$-test, $p<0.05$ ). No significant difference in sulfated GAG concentration was found when comparing the two non-pregnant cases. These results are in good agreement with previous reports in the literature for total sulfated GAG content $[4,5,15]$.

\subsection{Fluorophore-assisted carbohydrate electrophoresis (FACE) GAG assay}

Fig. 1 shows a typical FACE result for pregnant and nonpregnant human cervical tissue. The following disaccharides were detected in human cervical tissue: chondroitin disaccharide $\Delta \mathrm{di}$ $0 \mathrm{~S}$, chondroitin disaccharide $\Delta \mathrm{di}-4 \mathrm{~S}$, chondroitin disaccharide $\Delta \mathrm{di}$ $6 \mathrm{~S}$, and hyaluronic acid disaccharide $\Delta$ di-HA. A $31 \%$ and $132 \%$ increase in $\Delta$ di-6S and $\Delta$ di-HA, respectively, was found when comparing pregnant tissue to non-pregnant tissue (Student's $t$ test, $p<0.05$ ). A decrease in the mean amount of $\Delta$ di-4S for the pregnant tissue when compared to the non-pregnant tissue can be noted. However, this finding is not statistically significant due to the large variability and the low number of samples. No significant difference was found in the amount of the different disaccharides when comparing the two non-pregnant cases.

\subsection{Collagen concentration-hydroxyproline assay}

Mean collagen concentration was found to be $\sim 74 \%$. No statistically significant difference in the collagen concentration was found between the obstetric history cases. This result is consistent with reports in the literature $[2,8,9]$.

\subsection{Collagen extractability (solubility)}

A significant increase in the collagen solubility was found for the pregnant tissue ( $\sim 80 \%)$ when compared to the non-pregnant tissue $(\sim 37 \%)$ (Student's $t$-test, $p<0.05)$. No statistically significant difference was found when comparing the two non-pregnant cases. These trends are in agreement with previous reports in the literature $[4,6,8,9,11,12]$.

\subsection{Masson's trichrome stain and light microscopy}

A series of images of non-pregnant human cervical tissue at different levels of magnifications is presented in Fig. 2. The dense (bright blue stain) collagen network is the predominant tissue component, with small $(\sim 10 \mu \mathrm{m})$ fibroblasts interspersed within the collagen network, discernible by the dark-blue/black stain of their nuclei. Smooth muscle cells are stained red and appear to

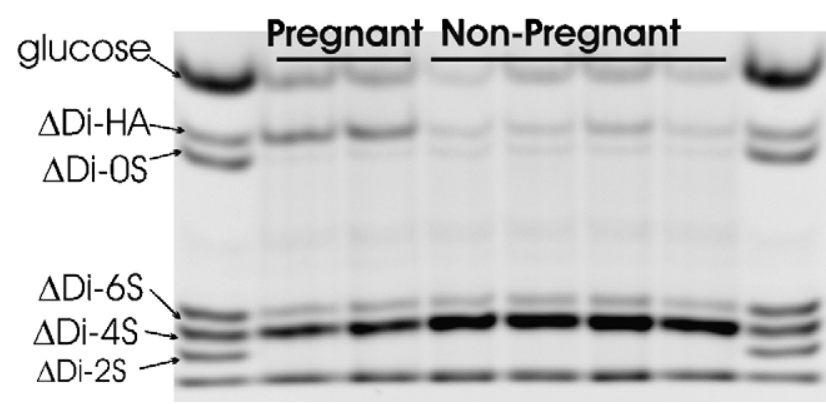

Fig. 1. Representative FACE result showing the presence of chondroitin disaccharide $\Delta$ di-0S, chondroitin disaccharide $\Delta$ di-2S, chondroitin disaccharide $\Delta$ di-4S, chondroitin disaccharide $\Delta$ di-6S, and hyaluronic acid disaccharide $\Delta$ di-HA from both pregnant and non-pregnant human cervical tissue. The two end lanes of the gel represent the disaccharide standards, and the middle lanes are the experimental samples. 

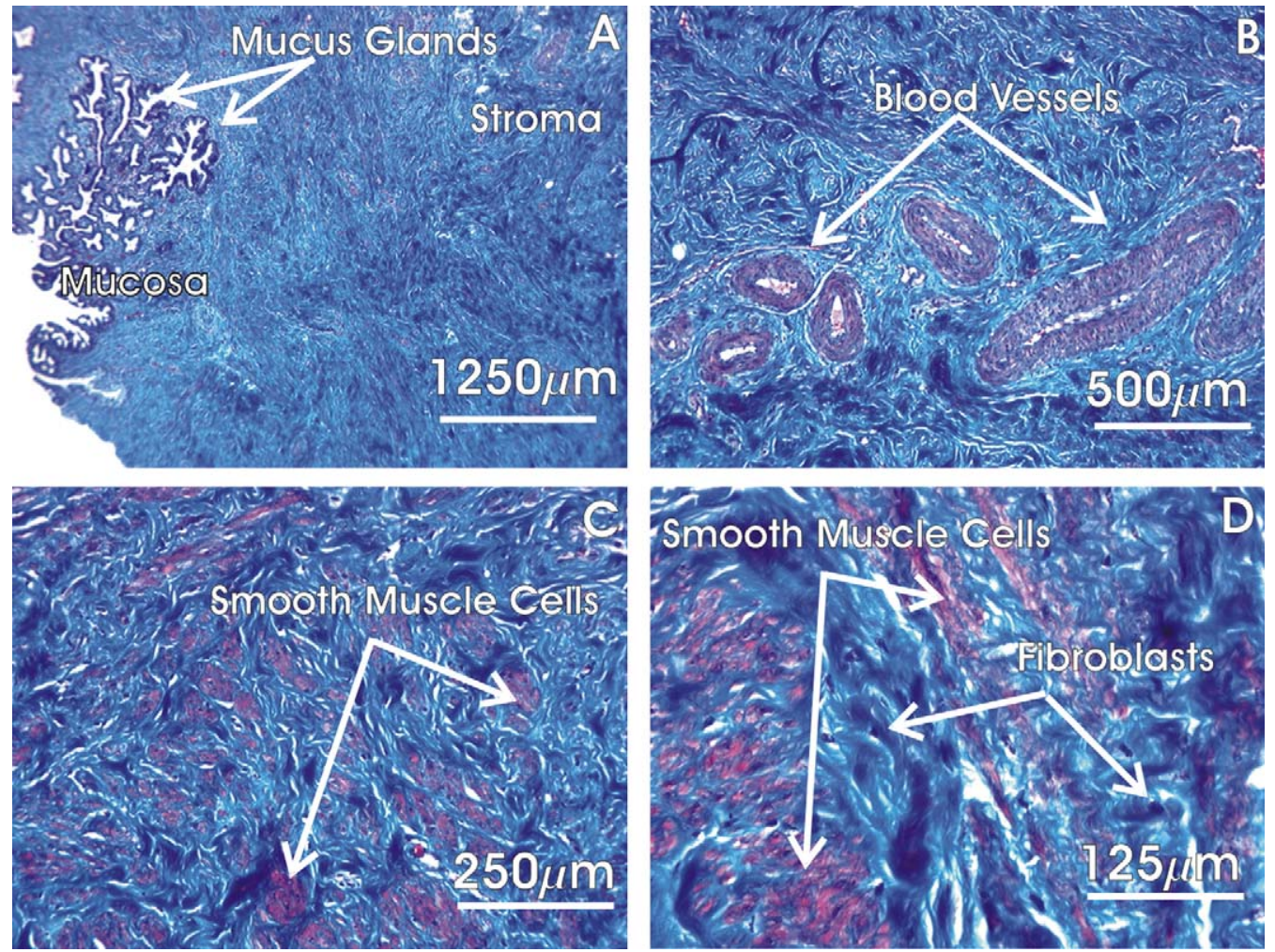

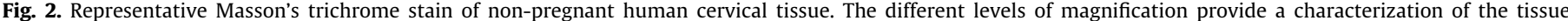

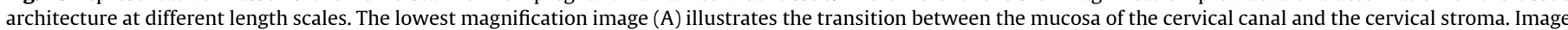

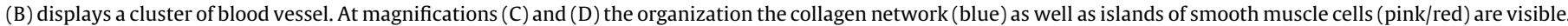

form small clusters of 50-250 $\mu \mathrm{m}$ size nested within the collagen network; at the higher magnifications, the collagen fibers can be seen to follow the perimeter of the cells. Small blood vessels, 100 $500 \mu \mathrm{m}$ in diameter, also tend to cluster and appear surrounded by collagen fibers following the vessels contours.

\subsection{Sirius Red stain and polarized light microscopy}

Fig. 3 shows representative polarized light images for a nonpregnant and pregnant tissue sample. The mean values for the organized collagen area fractions in the non-pregnant and pregnant samples in Fig. 3 are, respectively, 68\% and 32\%, with standard deviations between measurements at different locations of $7 \%$ and $4 \%$. These measurements are qualitative in nature, as the absolute percent value depends on the selected threshold grey level in the image analysis. Nevertheless, the higher level of organization of the collagen network in well defined oriented bundles for the non-pregnant tissue is apparent, while the collagen network for the pregnant tissue appears more diffuse and sparse with an increased interfiber distance. These results confirm trends reported in the literature $[4,28,29]$.

\subsection{Second harmonic generation}

Fig. 4 shows representative SHG images for the non-pregnant and pregnant tissue, respectively. The plane of the images in Fig. 4 is perpendicular to the anatomical longitudinal axis of the cervix, with the radial and circumferential directions marked accordingly
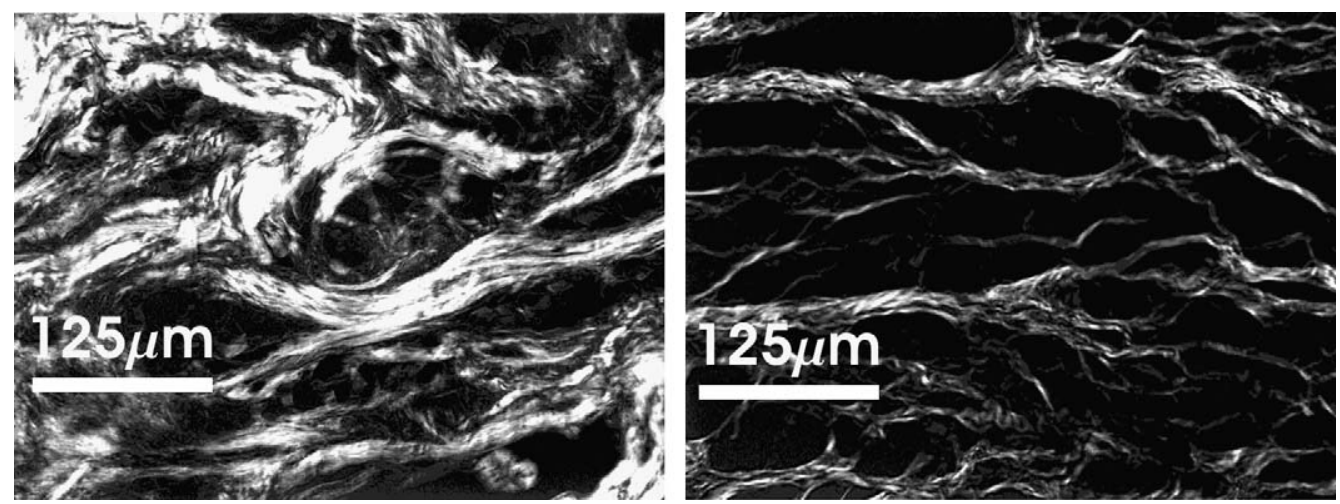

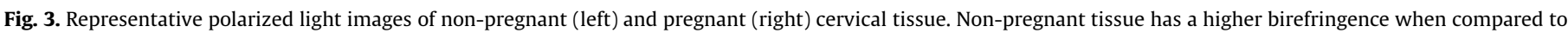

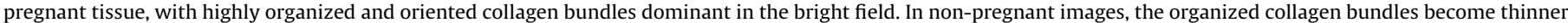

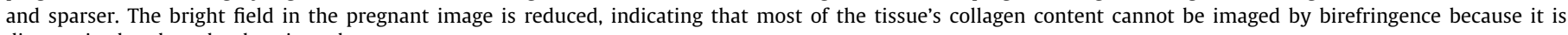
disorganized and randomly oriented. 

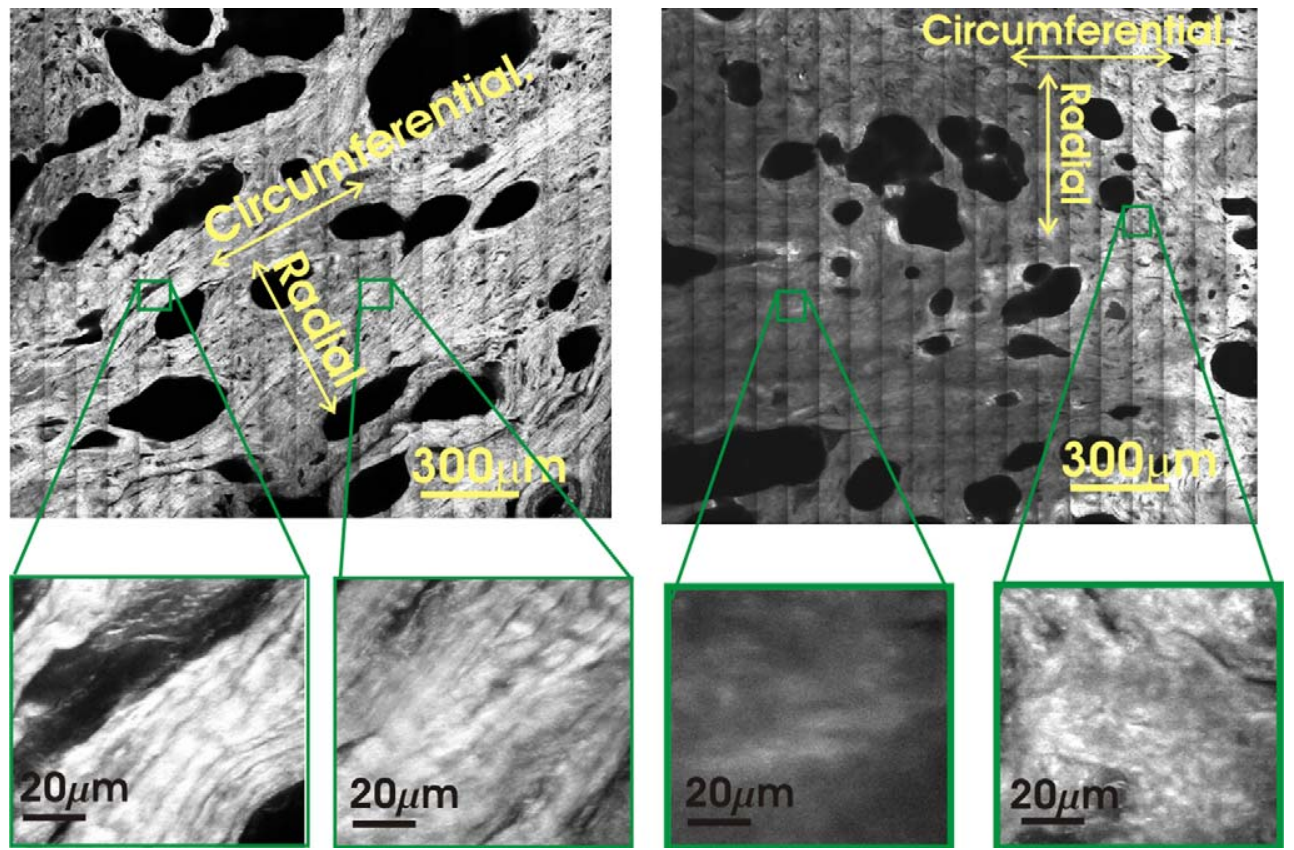

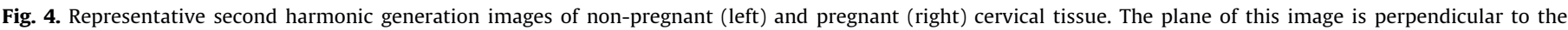

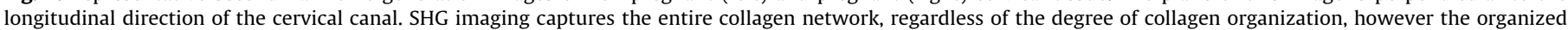
collagen in the non-pregnant tissue is associated with a sharper signal.

on the figures. At $890 \mathrm{~nm}$ laser excitation, the fluorescence emitted by cells due to endogenous fluorescent molecules is negligible, therefore the detected signal can be attributed entirely to SHG emitted by collagen. The (larger) islands of smooth muscle cells and the individual fibroblasts appear as lacunae in the collagen network, which is organized in fibers and bundles surrounding the cellular regions. A degree of preferential alignment of the collagen network along the anatomical circumferential direction is apparent in the large-scale images of these particular specimens. In the images at higher magnification, individual collagen fibers are visible and display their characteristic wavy and kinked configuration. Inspection of the images at smaller length scale shows a higher level of organization for the fibril in the non-pregnant tissue. Qualitatively, the signal for pregnant tissue tends to appear weaker, and less sharp when compared to the signal for the nonpregnant tissue.

\section{Discussion}

This study provides preliminary evidence supporting the hypothesis that direct correlations can be established between the structural/biochemical characteristics of cervical tissue and its mechanical properties. When comparing pregnant tissue to nonpregnant tissue, we noted a significant increase in collagen solubility, total sulfated GAG concentration, and $\Delta$ di-HA disaccharide (hyaluronic acid) content. Morphological studies indicated that pregnancy is associated with decreased collagen organization. The broad spectrum of measurements performed in this study yielded a comprehensive set of data on the biochemical constituents and morphological appearance of human cervical stroma, and on changes associated with pregnancy.

The elevated collagen solubility reflects the increase in collagen turnover associated with pregnancy, where the mature and densely cross-linked collagen network of the non-pregnant tissue is gradually replaced by newly synthesized collagen with a lower degree of crosslinking. Cross-link density has been found to correlate with the mechanical "strength" of collagenous tissue (see, e.g. $[30,31])$. The same cervical specimens assayed in the current study were subjected to mechanical testing in the parallel study [17], and the stress response of the tissue was captured using a minimal set of model parameters generated by fitting a timedependent rheological model to the experimental data. When comparing model parameters for the different obstetric history cases, we found a statistically significant increase for the pregnant tissue in the material parameter conceptually associated with the collagen network limiting stretch: the pregnant tissue displayed increased extensibility consistently with the inferred decrease in cross-link density [17].

The increase in tissue hydration can be mainly ascribed to the higher GAG concentration, particularly the HA fraction to the detriment of the (collagen binding) SLRPs. In previous studies (see, e.g. [16]), higher HA content in cervical tissue was found to be associated with increases in collagen interfibrillar spacing and network disorganization. Correspondingly, in the study [17] we found that pregnant tissue was associated with significantly lower values for parameters that can be conceptually associated with the strength of the bonds between the collagen network and the hydrated ground substance.

The preliminary results of the FACE assay provide a novel insight into the possible role of fine structure changes in glycosaminoglycans associated with cervical remodeling. This study was motivated by the results of studies in the literature where changes in the relative abundance of $4 \mathrm{~S}$ and $6 \mathrm{~S}$ terminals were identified in the transition from fetal to adult collagenous tissue in cartilage [32,33] and heart valves [34], as well as in association with pathological tissue conditions [21,35]. The statistically significant increase in the 6-sulfation fraction observed in pregnant tissue warrants further investigation of the role of these shifts in the modulation of cervical remodeling, as well as in pathological conditions, such as cervical insufficiency.

The preliminary results of the imaging study provide quantitative information on the organization of collagen fibers and qualitative information related to the sub-micron organization of collagen fibrils. The conventional Masson's trichrome stain assay is suitable to identify the general features of the tissue architecture and composition, but does not provide an accurate evaluation of 
the architecture of the collagen network, as other tissue components are also stained blue. The polarized light microscopy technique provides a convenient approach to quantify the morphology of organized/locally bundled collagen, but does not effectively image the optically isotropic/disorganized collagen fibers of pregnant tissue. The novel protocol relying on SHG imaging appears to be optimally suited to characterize the architecture of the collagen network in both pregnant and nonpregnant specimens. Among the advantages of SHG imaging, compared to more traditional imaging methods, we note that the SHG protocol: (1) provides information about 3D collagen architecture of ex vivo samples with minimal specimen sectioning (eliminating cutting artifacts) and photo-damage; (2) does not require fixation and staining; and (3) relies on the unique collagen SHG spectral signature, thus eliminating all artifacts from other tissue components. The images in Fig. 4 provide a complete and selective representation of the collagen content. Architectural features of the collagen organization, such as the presence of collagen-free lacunae in the $50-250 \mu \mathrm{m}$ range, cannot be confidently gleaned based on the traditional staining techniques. On the other hand, the trichrome images offer a direct interpretation of these lacunae, which appear to be associated with clusters of muscle cells. The macroscopic directions of preferential alignment for the collagen network were found to be consistent with indications in the literature [13,14]. The lower contrast of the second harmonic signal for the pregnant tissue can be ascribed, among other reasons, to a qualitative change in the collagen fibril organization. The sharper signal in the non-pregnant tissue is associated with regularly organized collagen bundles, while the "cottony" appearance of the images for the pregnant tissue is associated with a disrupted/disorganized fiber network. A quantitative correlation between second harmonic signal and the degree of organization in the collagen structure is still an active area of research [36]. Nevertheless, SHG imaging appears to be a powerful technique to characterize the collagen network of cervical tissue.

Statistically significant differences between the characteristics of the NPND and NPPD groups were not observed, likely due to the relatively low number of specimens and large observed biologic variability. Multiparity is known to be associated with faster labors [37]. Although it is likely that multiparity is associated with changes in the cervical ECM, our study did not have sufficient statistical power to detect these changes.

In conclusion, this biochemical study represents a critical intermediate step in pursuing an investigation of the structurefunction relationships in cervical tissue. The biochemical and morphological results of this study complement the mechanical characterization of the tissue $[7,17]$ by identifying changes in the collagen and GAG networks associated with tissue remodeling in pregnancy. Preliminary qualitative correlations can be inferred between the structural/biochemical characteristics of cervical tissue and its mechanical properties. Further analysis of the results of these studies is needed to determine the statistical significance of quantitative correlations between tissue composition and mechanical properties for each specimen.

\section{Condensation}

In an investigation of biochemistry and morphology of human cervices, normal pregnancy is associated with significant changes in concentration and organization of extracellular matrix constituents.

\section{Conflict of interest}

None.

\section{Acknowledgements}

We acknowledge the support of the Whitaker Foundation Biomedical Engineering Research Grant RG-02-0803, the National Science Foundation Graduate Research Fellowship, and the Society for Maternal Fetal Medicine-American Association of Obstetrician Gynecologists Foundation Scholarship. The authors would like to thank Professor Edward Chien and Dr. Huiling Ji for assistance with the FACE protocol, and Professor Peter So for giving us access to the SHG equipment. We also appreciate the support of the Departments of Gynecology and Pathology at Tufts Medical Center.

\section{References}

[1] Granström L, Ekman G, Ulmsten U, Malmström A. Changes in the connective tissue of corpus and cervix uteri during ripening and labour in term pregnancy. Br J Obstet Gynaecol 1989;96(October (10)):1198-202.

[2] Leppert PL, Yu SY. The extracellular matrix of the uterus, cervix and fetal membranes: synthesis, degradation and hormonal regulation. In: Chapter 5 elastin and collagen in the human uterus and cervix. Perinatology Press; 1991.

[3] Uldbjerg N, Ekman G, Malmstrom A, Olsson K, Ulmsten U. Ripening of the human uterine cervix related to changes in collagen, glycosaminoglycans, and collagenolytic activity. Am J Obstet Gynecol 1983;147(November (6)):662-6.

[4] Danforth DN. The effect of pregnancy and labor on the human cervix: changes in collagen, glycoproteins, and glycosaminoglycans. Am J Obstet Gynecol 1974;120(November (3)):641-51.

[5] Shimizu T, Endo M, Yosizawa Z. Glycoconjugates (glycosaminoglycans and glycoproteins) and glycogen in the human cervix uteri. Tohoku J Exp Med 1980;131:289-99.

[6] Rechenberger T, Uldbjerg N, Oxlund H. Connective tissue changes in the cervix during normal pregnancy and pregnancy complicated by cervical incompetence. Obstet Gynecol 1988;71:563-7.

[7] Myers KM, Paskaleva A, House MD, Socrate S. Mechanical and biochemical properties of human cervical tissue. Acta Biomater 2008;4:104-16.

[8] Maillot K, Zimmermann BK. The solubility of collagen of the uterine cervix during pregnancy and labour. Arch Gynecol Obstet 1976;220(4):275-80.

[9] Kleissl HP, Van Der Rest M, Naftolin F, Glorieux FH, De Leon A. Collagen changes in the human uterine cervix at parturition. Am J Obstet Gynecol 1978;130:748-53.

[10] Garfield RE, Saade G, Chwalisz K, et al. Control and assessment of the uterus and cervix during pregnancy and labour. Hum Reprod Update 1998;4(5):673-95.

[11] Ito A, Kitamura K, Mori Y, Hirakawa S. The change in solubility of type I collagen in human uterine cervix in pregnancy at term. Biochem Med 1979;21(3):262-70.

[12] Granstrom L, Ekman G, Malmstrom A. Insufficient remodelling of the uterine connective tissue in women with protracted labour. BJOG 1991;98(12):1212-6.

[13] Aspden RM. Collagen organisation in the cervix and its relation to mechanical function. Collagen Rel Res 1988;8:103-12.

[14] Weiss S, Jaermann T, Bajka M, et al. Three-dimensional fiber architecture of the nonpregnant human uterus determined ex vivo using magnetic resonance diffusion tensor imaging. Anat Rec A Discov Mol Cell Evol Biol 2006;288:84-90.

[15] Rath W, Osmers R, Severenyi M, Stuhlsatz HW, Kuhn W. The extracellular matrix of the uterus, cervix and fetal membranes: synthesis, degradation and hormonal regulation. Chapter 10, changes of glycosaminoglycans in cervical connective tissue. Perinatology Press; 1991.

[16] Maradny EE, Kanayama N, Terao T, et al. The role of hyaluronic acid as a mediator and regulator of cervical ripening. Hum Reprod 1997;2(5):1080-8.

[17] Myers KM, Paskaleva A, House MD, Socrate S. A study of the anisotropic and tension/compression behavior of human cervical tissue. J Biomech Eng; in press.

[18] Petersen LK, Uldbjerg N. Cervical collagen in non-pregnant women with previous cervical incompetence. Eur J Obstet Gynecol Reprod Biol 1996;67:41-5.

[19] Farndale RW, Sayers CA, Barrett AJ. A direct spectrophotometric microassay for sulfated glycosaminoglycans in cartilage cultures. Connect Tissue Res 1982;9: 247-8.

[20] Calabro A, Midura R, Wang A, West L, Plaas A, Hascall VC. Fluorophore-assisted carbohydrate electrophoresis (FACE) of glycosaminoglycans. Osteoarthritis Cartilage 2001;9:16-22.

[21] Plaas AH, West LA, Thonar EJA, et al. Altered fine structures of corneal and skeletal keratin sulfate and chondroitin/dermatan sulfate in macular corneal dystrophy. J Biol Chem 2001;276(October (43)):39788-96.

[22] Woessner JF. Methodology of connective tissue research. In: Determination of hydroxyproline in connective tissues. Oxford: Joynson-Bruvvers Ltd.; 1976.

[23] Stegeman H, Stalder K. Determination of hydroxyproline. Clin Chem Acta 1967; 18:267-73.

[24] Conn HJ, Darrow MA. Staining procedures used by the biological stain commission. Baltimore: Williams \& Wilkins; 1960.

[25] Clark K, Ji H, Feltovich H, Janowski J, Carroll C, Chien EK. Mifepristone-induced cervical ripening: structural, biomechanical, and molecular events. Am J Obstet Gynecol 2006;194(5):1391-8.

[26] Campagnola PJ. Second-harmonic imaging microscopy for visualizing biomolecular arrays in cells, tissues and organisms. Nat Biotechnol 2003;21(11) 1356-60. 
[27] Buehler C, Kim KH, Greuter U, Schlumpf N, So PTC. Single-photon counting multicolor multiphoton fluorescence microscope. J Fluoresc 2005;15(1):41-51.

[28] Aspden RM. The theory of fibre-reinforced composite materials applied to changes in the mechanical properties of the cervix during pregnancy. J Theor Biol 1988;130:213-21.

[29] Yu SY, Tozzi CA, Babiarz J, Leppert PC. Collagen changes in rat cervix in pregnancy-polarized light microscopic and electron microscopic studies. Exp Biol Med 1995;209(4):360-8.

[30] Guilak F, Ratcliffe A, Lane N, Rosenwasser MP, Mow VC. Mechanical and biochemical changes in the superficial zone of articular cartilage in canine experimental osteoarthritis. J Orthop Res 1994;12(July (4)):474-84.

[31] Williamson AK, Chen AC, Masuda K, Thonar E, Sah RL. Tensile mechanical properties of bovine articular cartilage: variations with growth and relationships to collagen network components. J Orthop Res 2003;21(September (5)):872-80.

[32] Calabro A, Hascall VC, Midura RJ. Adaptation of FACE methodology for microanalysis of total hyaluronan and chondroitin sulfate composition from cartilage. Glycobiology 2000;10(March (3)):283-93.
[33] Plaas AHK, WongPalms S, Roughley PJ, Midura RJ, Hascall VC. Chemical and immunological assay of the nonreducing terminal residues of chondroitin sulfate from human aggrecan. J Biol Chem 1997;272(August (33)):20603-10.

[34] Stephens EH, Chu CK, Grande-Allen KJ. Valve proteoglycan content and glycosaminoglycan fine structure are unique to microstructure, mechanical load and age: relevance to an age-specific tissue-engineered heart valve. Acta Biomater 2008;4(September (5)):1148-60.

[35] Plaas AHK, West LA, Wong-Palms S, Nelson FRT. Glycosaminoglycan sulfation in human osteoarthritis-disease-related alterations at the non-reducing termini of chondroitin and dermatan sulfate. J Biol Chem 1998;273(May (20)): 12642-9.

[36] LaComb R, Nadiarnykh O, Townsend SS, et al. Phase matching considerations in second harmonic generation from tissues: effects on emission directionality, conversion efficiency and observed morphology. Opt Commun 2008;281(7): 1823-32.

[37] Friedman EA, Kroll BH. Computer analysis of labor progression III. Pattern variations by parity. J Reprod Med 1971;6(4):63-7. 